\title{
The influence of biodegradable mulches on the yielding of autumn raspberry (Rubus idaeus L.)
}

\author{
Katarzyna Król-Dyrek ${ }^{1 *}$, Piotr Siwek ${ }^{2}$ \\ ${ }^{1}$ Niwa Berry Plant Breeding Ltd. \\ Brzezna 565, 34-606 Brzezna, Poland \\ ${ }^{2}$ Department of Vegetable and Medicinal Plants \\ University of Agriculture in Krakow \\ 29 Listopada 54, 31-425 Kraków, Poland
}

\begin{abstract}
A three-year experiment was set up to assess the effect of three mulch types on the growth and yield of 'Polka' autumn fruiting raspberry (Rubus idaeus L.). The experimental arrangement comprised four combinations of two parallel blocks, one of which was a field crop and the second was a covered crop in the form of a high tunnel with raised beds sides. The crop was grown on raised beds (approximately $30 \mathrm{~cm}$ high) covered with a mulch made of: 1) polypropylene non-woven (PP); 2) PP with a photodegradant; 3) polylactide nonwoven (PLA). A crop on a raised bed without any mulch was the control. Biometric, physiological and yield parameters were assessed and included the number of canes, plant height, chlorophyll content in the leaves, fruit yield, weight of 20 fruits and the extract content.

The obtained results show that the height of the canes grown on PLA and PP mulch was significantly higher than for the PP with photodegradant. Cultivation on PP, PLA and PP with photodegradant mulch resulted in a significant increase in the weight of 20 raspberry fruits and higher chlorophyll content in the leaves compared to the control combination.
\end{abstract}

Key words: cultivation, soil cover, growth, Brix

\section{INTRODUCTION}

Obtaining high-quality fruit and a high yield of raspberries for the dessert fruit market involves the introduction of new cultivation technology, such as covering (covers, tunnels), cultivation on raised bed, mulching, optimal fertilisation and irrigation.

The lack of registered herbicides for dicotyledonous weed control and cost-consuming hand weeding has led to many crop growers introducing different kinds of mulches. They are designed to protect the soil from weeds and reduce moisture loss from the soil. In addition, some studies have shown that the use of herbicides reduces the chlorophyll content and the number of leaves (Freeman et al. 1966).

Young raspberry plants are especially delicate, therefore it is advisable to eliminate weed competition or the use of chemicals and to give them a favourable microclimate for development through the use of mulches (Trinka and Pritts 1992). Research on the use of mulches in the cultivation of many species of plants indicates their positive impact on plant growth and yield (Briassoulis 2007, Moreno and Moreno 2008). Mulching can also be used on plantations of strawberries, raspberries, orchards of fruit trees 
and the cultivation of ornamental plants (Siwek and Libik 2012). Studies have shown that raspberries planted on mulches such as bark, sawdust or paper have a higher efficiency than control plants without the use of a soil cover or black polyethylene mulch (Warmund et al. 1995). In addition, cultivation on mulch and elevated fields reduces the likelihood of the dangerous root disease Phytophthora, thanks to which such experiments were able to obtain an almost fourfold increase in yield compared to the control without mulches (Heiberg 1999).

The use of mulches made of non-biodegradable materials creates a problem after the cultivation of the crop. The solution may be using new biodegradable and composting materials, produced using plant components such as starch or vegetable oils, which have a similar mechanical strength as conventional film materials (Girgenti et al. 2012).

The aim of this study was to examine the effectiveness of biodegradable mulches on growing raspberries in the first three years of fruiting, on raised beds in cultivation under covers and without covers.

\section{MATERIAL AND METHODS}

The plantation was established in autumn 2010 in the Orchard Department of the Experimental Institute of Horticulture in Brzezna on class III quality soil, defined as average clay. The study was conducted for three years, from 2011 to 2013, on the autumn fruiting raspberry (Rubus idaeus L.) 'Polka'. The experimental arrangement comprised four combinations of two parallel blocks, one of which was a field crop and the second was a covered crop in the form of a high tunnel with raised beds (foil tunnel structure with a width of 4.5 $\mathrm{m}$ and a height of $3 \mathrm{~m}$, a film disposed on the belt structure, where the edges reached about $1 \mathrm{~m}$ above the ground). Each combination was represented by 20 plants (four replicates of five plants each). The plants were planted in the free standing rows of approximately $70 \mathrm{~cm}$. In autumn all of the canes were cut to a height of $5-10 \mathrm{~cm}$.

In spring 2011 mulches were placed in the rows of plants. In spring 2012 the crops were supplemented with used prototypes of polypropylene non-woven with photodegradant (PP photodegradant) mulch and polylactide non-woven (PLA) mulch. The improved versions of these materials were introduced: PP nonwoven fabric contained $0.02 \%$ photodegradant (iron stearate) and the PLA nonwovens do not shrink under the influence of temperature. The experimental in the open field and under a tunnel blocks consisted of the folowing combinations:

1. the method of planting was on a raised bed (approximately $30 \mathrm{~cm}$ high), covered by a mulch made of polypropylene nonwoven with a photodegradant (PP photo) at a weight of $50 \mathrm{~g} \mathrm{~m}^{-2}$;

2. the method of planting was on a raised bed covered by mulch made of polylactide nonwoven (PLA) with a weight of $50 \mathrm{~g} \mathrm{~m}^{-2}$;

3. the method of planting was on a raised bed covered by mulch made of polypropylene non-woven (PP) with a weight of $50 \mathrm{~g} \mathrm{~m}^{-2}$;

4. the method of planting was on a raised bed without mulch as the control.

Every year in the spring compound fertilisers were used in both blocks. Chemical protection was carried out in accordance with the timetable of plant protection. The plots were irrigated using a T-tape irrigation system.

The number of canes and plant height were noted, the chlorophyll content in the leaves was measured, fruit yield from the plot (five plants) and the weight of 20 fruits from each set were determined. Ripe fruit were harvested and divided into commercial and non-commercial (rotten, decaying) yields. Total soluble solids content ( $\left.{ }^{\circ} \mathrm{Brix}\right)$ in fruits was measured two times every season (18, 24.08.2011; 1, 20.08.2012; 5, 19.08.2013) using a PR 101refractometer, according to Polish Standard PN - EN 12143: 2000. Measurements of the chlorophyll content in leaves were performed using a SPAD-502 (SPAD units). All results (depending on the year and type of mulch, separately: number of canes, plant height, chlorophyll content in leaves, fruit yield and the weight of 20 fruits) were subjected to an analysis of variance and a Duncan test at a significance level of $\mathrm{p}=0.05$.

\section{RESULTS}

The height of canes differed depending on the growing block; significantly higher plant canes formed under the covers. Plant height differed significantly depending on the year, with the highest canes grown in 2013 and the lowest in 2011. The height of canes also depended on the mulch used; PP photodegradant mulch had the lowest canes and the highest were found in the non-woven fabric with PLA (Tab. 1). The number of canes also differed depending on the year. The plants produced the highest number of canes in 2013 and the lowest in 2011. In the control plants and those under PLA mulch, the number of canes did not 
Table 1. Height, number of canes and chlorophyll content in leaves of raspberry cultivar 'Polka' depending on the year, mulching material and covering

\begin{tabular}{llccc}
\hline Treatment & & $\begin{array}{c}\text { Plant height } \\
(\mathrm{cm})\end{array}$ & $\begin{array}{c}\text { Number of canes } \\
(\mathrm{pcs})\end{array}$ & $\begin{array}{c}\text { Chlorophyll content } \\
\text { (SPAD) }\end{array}$ \\
\hline \multirow{3}{*}{ Year } & 2011 & $127.0 \mathrm{a} *$ & $2.7 \mathrm{a}$ & $39.9 \mathrm{c}$ \\
& 2012 & $161.3 \mathrm{~b}$ & $9.9 \mathrm{~b}$ & $38.2 \mathrm{~b}$ \\
\hline \multirow{4}{*}{ Mulch } & 2013 & $172.1 \mathrm{c}$ & $10.9 \mathrm{c}$ & $35.6 \mathrm{a}$ \\
& PP with photodegradant & $149.8 \mathrm{a}$ & $7.1 \mathrm{a}$ & $38.4 \mathrm{bc}$ \\
& Control & $152.2 \mathrm{ab}$ & $9.1 \mathrm{~b}$ & $36.9 \mathrm{a}$ \\
\hline \multirow{2}{*}{ Average of covers } & $155.4 \mathrm{~b}$ & $6.7 \mathrm{a}$ & $38.6 \mathrm{c}$ \\
& PP & $156.5 \mathrm{~b}$ & $8.6 \mathrm{~b}$ & $37.6 \mathrm{ab}$ \\
\hline
\end{tabular}

*Values marked with the same letters do not differ significantly for $\mathrm{p}=0.05$

differ significantly and was higher compared to the other combinations. Significant differences in the number of canes obtained depended on the method of cultivation; more canes were produced in the plants grown without covers (Tab. 1).

The content of chlorophyll in leaves differed significantly depending on the year; in 2013, the chlorophyll content was the lowest, while it was the highest in 2011. Raspberry leaves cultivated under covers contained more chlorophyll in the leaves compared to the crops without covers. There was no significant difference of chlorophyll content for PP with photodegradant and for PP as well as for the control and for PLA (Tab. 1).

The sum of the marketable yield significantly differed depending on the year. In 2012 the obtained yield was notable highest, and in 2011 it was the lowest (first year of fruiting). The yield obtained on the PP with photodegradant differed significantly from the yield obtained in the control treatment. Quite different yielding results were obtained depending on the method of cultivation, and were higher for plants grown under covers as compared to the plants without covers (Tab. 2).

The sum of the non-commercial yield differed depending on the year. In 2011, there was no noncommercial yield, and in other years, there were no differences. The type of mulch did not have an impact on the amount of non-commercial fruits, although the plants grown on PLA mulch had the smallest non-commercial crop. Cultivation under covers resulted in a markedly lower level of this kind of yield than in cultivation without covers (Tab. 2).

The weight of 20 fruits differed significantly depending on the year of the study. It was the largest in 2011 and in 2013 the weight of 20 fruits was the smallest. Differences in the 20 fruits weight were noted depending on which mulch the plants were grown on. The highest weight of 20 fruits was on PP mulch, although not significantly different from the weight of the fruits grown on the PLA and PP with photodegradant mulch. The smallest mass of fruits was obtained from the control. In addition, cultivation under covers resulted in a higher

Table 2. The sum of marketable and non-marketable yield, and the mass of 20 raspberry fruits of the 'Polka' cultivar depending on the year, mulching material and covering

\begin{tabular}{llccc}
\hline Specification & & $\begin{array}{c}\text { Marketable yield } \\
\text { (g per plant) }\end{array}$ & $\begin{array}{c}\text { Non-marketable yield } \\
\text { (g per plant) }\end{array}$ & $\begin{array}{c}\text { Mass of 20 fruits } \\
(\mathrm{g})\end{array}$ \\
\hline \multirow{3}{*}{ Year } & 2011 & $900 \mathrm{a}$ & $0.00 \mathrm{a}$ & $90.30 \mathrm{c}$ \\
& 2012 & $1480 \mathrm{c}$ & $25.52 \mathrm{~b}$ & $68.50 \mathrm{~b}$ \\
\hline \multirow{3}{*}{ Mulch } & 2013 & $1280 \mathrm{~b}$ & $22.60 \mathrm{~b}$ & $57.70 \mathrm{a}$ \\
& PP photodegradant & $1140 \mathrm{a}$ & $15.38 \mathrm{a}$ & $72.00 \mathrm{~b}$ \\
& Control & $1280 \mathrm{~b}$ & $19.40 \mathrm{a}$ & $70.00 \mathrm{a}$ \\
\hline \multirow{2}{*}{ Average of covers } & $1240 \mathrm{ab}$ & $15.04 \mathrm{a}$ & $73.50 \mathrm{~b}$ \\
& PP & $1200 \mathrm{ab}$ & $14.34 \mathrm{a}$ & $73.10 \mathrm{~b}$ \\
\hline
\end{tabular}

*Explanation: see Table 1 
Table 3. Total soluble solids content in the raspberry fruits of the 'Polka' cultivar depending on the year, mulching material and covering

\begin{tabular}{llcc}
\hline Specification & & ${ }^{\circ}$ Brix first term & ${ }^{\circ}$ Brix second term \\
\hline \multirow{3}{*}{ Year } & 2011 & $9.5 \mathrm{a}^{*}$ & $10.3 \mathrm{~b}$ \\
& 2012 & $10.1 \mathrm{~b}$ & $10.0 \mathrm{a}$ \\
\hline \multirow{3}{*}{ Mulch } & 2013 & $11.3 \mathrm{c}$ & $12.3 \mathrm{c}$ \\
& PP photodegradant & $10.5 \mathrm{c}$ & $10.8 \mathrm{a}$ \\
& Control & $10.3 \mathrm{~b}$ & $10.9 \mathrm{~b}$ \\
\hline \multirow{2}{*}{ Average of covers } & PP & $10.4 \mathrm{c}$ & $10.9 \mathrm{~b}$ \\
& PLA & $10.1 \mathrm{a}$ & $11.0 \mathrm{c}$ \\
\hline
\end{tabular}

*Explanation: see Table 1

20 fruits weight than those grown without covers (Tab. 2).

In the first period of Brix extract measurement there were significant differences depending on the year. The values were the lowest in 2011 and the highest in 2013. The fruits obtained from PP with photodegradant and PP had the highest Brix content (no significant difference), and the lowest came from the PLA non-woven mulch. Fruits obtained from control had a higher Brix content than fruit cultivated with covers.

In the second measurement period, the highest values of Brix in fruits were obtained in 2013, and the lowest in 2012. Cultivation on the PLA mulch resulted in the highest Brix content in fruits, and the PP with photodegradant mulch had the lowest. Also, in the second measurement period the fruits of covered crops had significantly lower levels of Brix (Tab. 3).

\section{DISCUSSION}

In the present research, younger plants produced lower canes and we obtained significantly higher canes for plants under covers, as in the study by $\mathrm{Xu}$ et al. (2014). The highest canes were obtained from soil that was covered for the entire season with PP (155.4 cm) and PLA $(156.5 \mathrm{~cm})$ mulches. In cultivation on PP with photodegradant mulch, where the ground cover was low and non-woven fabric was degraded by sunlight, the canes were the lowest $(149.8 \mathrm{~cm})$ and were slightly higher in the control $(152.2 \mathrm{~cm})$. In Gotame et al. (2013) the canes heights of 'Polka' were 131-147 cm. The positive effect of mulches on the number of canes produced was shown by Trinka and Pritts (1992), who used the mulches from straw and polyethylene in a year of planting 'Heritage' raspberries, and achieved a higher growth of canes in the first and second year of cultivation. The height of the canes in the first year was $78 \mathrm{~cm}$ for the control, $87 \mathrm{~cm}$ for black polyethylene mulch and $86 \mathrm{~cm}$ for straw.

In the current study, older plants produced more canes than plant in the first years of cultivation. The number of canes in the control and PLA mulch did not differ significantly (9.1 and 8.6, respectively) and was higher than in the combination with PP with photodegradant and PP (7.1 and 6.7, respectively). This differs from what is described in the literature. In 'Heritage' autumn raspberry cultivation, a $41 \%$ greater number of canes was obtained when using black polyethylene and $61 \%$ more with straw, as compared to the combination without mulches (Trinka and Pritts 1992). Similarly, other studies using mulches in blackberry cultivation proved the effectiveness of mulching, where in the first year of the experiment the plots that were mulched had $19.4 \%$ more annual canes than those without and about 54\% more annual canes in the second year (Rom 2001).

There were significant differences in the number of canes obtained depending on the method of cultivation: more canes were produced when plants were not covered - 8.7 compared to 7.0 for covered. In research by Krawiec et al. (2013) 'Polka' raspberry plants covered by flat covers with PP non-woven had more canes per plants than plants that were not covered.

The content of chlorophyll in leaves differed significantly depending on the crop year; the chlorophyll content was the lowest in 2013 and the highest in 2011. Raspberry leaves contained significantly higher chlorophyll in the leaves (38.9 SPAD units) in cultivation under covers compared to cultivation without covers (36.8 SPAD units). Similarly, in research by Chavarria et al. (2012), grape leaves grown under covers were characterised by a higher content of chlorophyll compared to the leaves of plants grown without covers - the first 
measurement by $41.1 \%$ and the second by $36.17 \%$. In a study by Nair (2012), lettuce grown under covers in plots covered with black mulch had lower chlorophyll content in leaves (27.9 SPAD units) than uncovered plots (29.4 SPAD units). The opposite results were obtained in the present experiment. We found lower levels of chlorophyll in the leaves of raspberries grown in the control (36.9 SPAD units), and higher levels in the leaves of raspberries grown in mulch, with the highest value found for PP mulch (38.6 SPAD units).

The sum of the non-commercial yield was low in all of the years of the research and the differences between the combinations were insignificant. The sum of the marketable yield significantly differed depending on the year. The highest marketable yield was obtained in the second year of the study, in 2012 (7.4 kg per five plants) and the lowest in the first, 2011 (4.5 kg per five plants). The average commercial yield of the three years of research was the lowest in PP with photodegradant (5.7 kg per five plants), while the control had the highest ( $6.4 \mathrm{~kg}$ per five plants). Additional data is described in the literature. In the experiment with mulching blackberry, Rom (2001) showed that mulched plots produced an average of $11 \%$ more than the total yield in the first year of fruiting and more significantly $43 \%$ more in the second year, compared with non-mulched plots. In this study, we obtained significantly different yielding results depending on the method of cultivation; it was higher in the cultivation under tunnel (6.9 kg per five plants) compared to plants in the field (5.3 kg per five plants). Growing raspberry plants under a tunnel resulted in more favourable growth conditions, allowing higher yielding. In $\mathrm{Xu}$ at el. (2014) for 'Polka', a high tunnel increased yield by $56.6 \%$ compared to an umbrella-like structure, and 2.3 times compared to the yield measured in the open field. Reflective mulch significantly increased yield by $13.6 \%, 14.8 \%$ and $29.5 \%$, respectively, under high tunnel, umbrella-like structure and open field.

The weight of 20 fruit differed significantly depending on the year. The highest weight of 20 fruit $(90.3 \mathrm{~g})$ was found for the first year of the study, in 2011, while the lowest (57.7 g) was in 2013. Significant differences in 20 fruit weight were found for the type of mulch used. The highest average 20 fruit weight of the three years of research was on PP mulch (73.5 g), although it was not significantly different from the weight of the fruit on the PP with photodegradant and PLA mulches (72.0 and
$73.1 \mathrm{~g}$, respectively). The lowest 20 fruit weight was found for the control $(70.0 \mathrm{~g})$. The data in the literature suggest that the use of crop mulches always increases the size of the fruit. Rom (2001) reports that in the first year of the study there were similar results in the combination with mulching and without mulching, but in the next year there were already significantly higher amounts of fruit in the plots with mulching. In the study by Mladin et al. (2008), the weight of raspberry fruit of the 'Polka' cultivar with conventional tillage (flat ground, without mulching) was only $66.6 \mathrm{~g}$.

In this study, cultivation under tunnels resulted in a higher 20 fruit weight than those grown without covers. Other results were obtained in $\mathrm{Xu}$ et al. (2014) study. It was no statistical differences in fruit weight obtained under tunnel umbrella-like structure compared with fruits from open field.

In the first period of Brix measurements there were significant differences depending on the year. 2011 was the lowest $\left(9.5^{\circ}\right.$ Brix) and 2013 was the highest $\left(11.3^{\circ} \mathrm{Brix}\right)$. In cultivation on mulch the highest Brix content in fruit was obtained from cultivation on PP non-woven with photodegradant $\left(10.5^{\circ}\right.$ Brix), and the lowest for PLA non-woven $\left(10.1^{\circ}\right.$ Brix). The field plots had higher Brix content in fruits $\left(10.9^{\circ} \mathrm{Brix}\right)$ compared to the covered ones $\left(9.7^{\circ} \mathrm{Brix}\right)$. In the second period of measurement of Brix in fruit, the highest Brix values were obtained in $2013\left(12.3^{\circ}\right.$ Brix $)$ and the lowest in $2012\left(10.0^{\circ}\right.$ Brix). In cultivation using PLA, Brix content in fruits was the highest $\left(11.0^{\circ} \mathrm{Brix}\right)$, and PP with photodegradant had the lowest $\left(10.8^{\circ} \mathrm{Brix}\right)$. In addition, fruits from covered plots had a significantly lower level $\left(10.3^{\circ} \mathrm{Brix}\right)$ compared to fruits from uncovered plots $\left(11.5^{\circ} \mathrm{Brix}\right)$ in the second period of measurements.

In conventional tillage, which is essentially flat without covers and without the use of mulches, fruit of the 'Polka' cultivar grown in Serbia had 14.0$14.4^{\circ}$ Brix, depending on the year (Milivojević et al. 2011), Romania had $11.7^{\circ}$ Brix (Mladin et al. 2008), and in Poland fruit of the 'Polka' cultivar had 9.8$9.9^{\circ}$ Brix (Skupień et al. 2011), or $11.4^{\circ}$ Brix (Danek and Markowski 2003).

\section{CONCLUSIONS}

1. The numbers of canes that grew on the control and PLA mulches were significantly higher than those for PP with photodegradant and PP.

2. Cultivation on PP, PLA and PP with photodegradant mulch resulted in higher leaf 
chlorophyll content and a significant increase in the mass of 20 raspberry fruit as compared to the control combination.

3. The highest marketable yield was obtained in the control combination but similar level of the yield was found for PP and PLA mulches. It was significantly higher in cultivation under the tunnel.

\section{ACKNOWLEDGEMENTS}

The research was supported by a project "Biodegradable fibre products" BIOGRATEX - POIG 01.03.01-00-007/08 co-financed from EU funds with European Program of Regional Development - Innovative Economy.

\section{REFERENCES}

Briassoulis D., 2007. Analysis of the mechanical and degradation performances of optimized agricultural biodegradable films. Polym. Degrad. Stab. 92: 11151132.

Chavarria G., Pessoa dos Santos H., Suita de Castro L.A., Marodin G.A.B., Bergamaschi H., 2012. Anatomy, chlorophyll content and photosynthetic potential in grapevine leaves under plastic cover. Rev. Bras. Frutic. 34(3): 661-668.

Danek J., Markowski J., 2003. The chemical composition of selected genotypes of raspberry as aqualitative culture. Folia Hort. Supl. 2003/2: 397-399.

Freeman J.A., Renney A.J., Driediger H., 1966. Influence of atrazine and simazine on leaf chlorophylls and fruit yield of raspberries. Can. J. Plant Sci. 46: 454455.

Girgenti V., Peano C., Giuggioli N.R., Giraudo E., Guerrini S., 2012. First results of biodegradable mulching on small berry fruits. Acta Hort. 926: 571576.

Gotame T.P., Andersen L., Petersen K.K., Ottosen C.O., Graham J., 2013. Chlorophyll fluorescence and flowering behaviour of annual-fruiting raspberry cultivars under elevated temperature regimes. Europ. J. Hort. Sci. 78(5): 193-202.

Heiberg N., 1999. Effects of raised beds, black soil mulch and oxadixyl on root rot (Phytophthora fragariae var. rubi) in red raspberry. Acta Hort. 505: 249-258.
KraWiec P., Szot I., Lipa T., 2013. Effect of felt covering on primo cane raspberry cultivars on their growth and yield. Episteme 20(2): 349-359.

Milivojević J. M., Nikolić M.D., DragišıćMaksimović J.J., Radivojević D.D., 2011. Generative and fruit quality characteristics of primocane fruiting red raspberry cultivars. Turk. J. Agric. For. 35: 289-296.

Mladin P., Coman M., Ancu I., Mladin G., Diaconu C., Chitu E., Nicolae S., 2008. Studies on the horticultural and breeding value of some strawberry, raspberry and blackberry genotypes. Fruit Grow. Res. XXIV: 48-55.

Moreno M.M., Moreno A., 2008. Effect of different biodegradable and polyethylene mulches on soil properties and production in a tomato crop. Sci. Hort. 116: 256-263.

NAIR A., 2012. Mulch and row cover affect lettuce production in high tunnels. Iowa State Research Farm Progress Reports: 34-38. Available online at http://fpr.extension.iastate.edu/pdf/2012/MulchRowCover.pdf

Rom C.R., 2001. The effect of mulch on early yields of 'Apache' blackberry. Hort. Stud 494: 26-27.

SiweK P., LiBIK A., 2012. Plastic covers in Polish horticulture. Plasticulture 131: 65-73.

Skupień K., Ochmian I., Grajkowski J., KrzywyGawrońsKa E., 2011. Nutrients, antioxidants, and antioxidant activity of organically and conventionally grown raspberries. J Appl. Bot. Food Qual. 84(1): 85-89.

Trinka D.L., PRiTTS M.P., 1992. Micropropagated raspberry plant establishment responds to weed control practice, row cover use, and fertilizer placement. J. Amer. Soc. Hort. Sci. 117(6): 874-880.

Warmund M.R., Starbuck C.J., Finn C.E., 1995. Plants mulched with recycled newspaper produce greater yields than those grown with black polyethylene. J. Small Fruit Vitic. 3(1): 63-73.

Xu Q., Gosselin A., Desjardins Y., Medina Y., Gauthier L., 2014. Red raspberries production under high tunnel, umbrella-like structure and open field under northern Canadian climate. Acta Hort. 1037: 771776.

Received July 8, 2014; accepted March 11, 2015 